\author{
INTERNATIONAL UNION OF \\ PURE AND APPLIED CHEMISTRY
}

MACROMOLECULAR DIVISION

COMMISSION ON MACROMOLECULAR NOMENCLATURE

\title{
NOMENCLATURE OF REGULAR SINGLE-STRAND ORGANIC POLYMERS
}

(RULES APPROVED 1975) 


\title{
NOMENCLATURE OF REGULAR SINGLE-STRAND ORGANIC POLYMERS
}

\author{
(RULES APPROVED 1975)
}

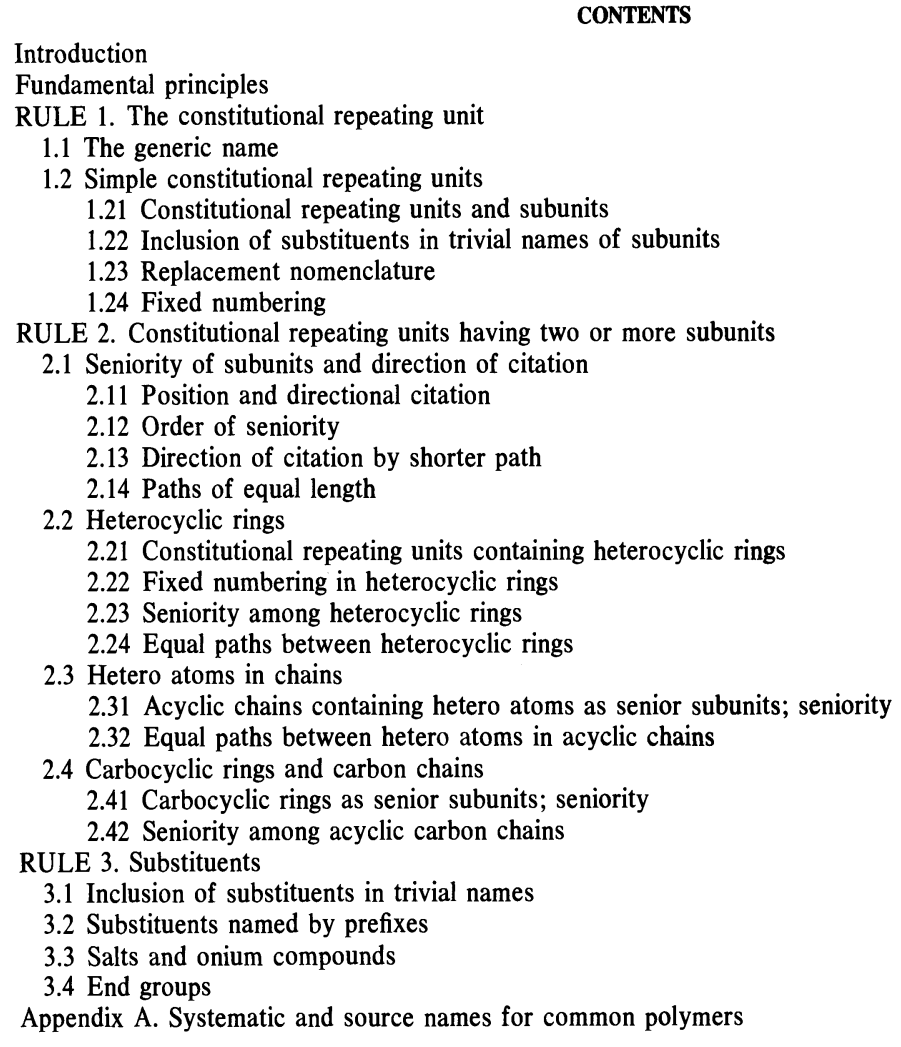

A regular single-strand polymer is one whose molecules can be described by constitutional repeating units with only two terminals composed of one atom each. See ref. 5.

\section{INTRODUCTION}

In 1952, the Subcommission on Nomenclature of the IUPAC Commission on Macromolecules published a report $^{1}$ on the nomenclature of macromolecules that included a method for the systematic naming of linear organic polymers on the basis of structure. A later report ${ }^{2}$ dealing with steric regularity utilized this system of

*Chairman: K. L. Loening (USA); Secretary: R. B. Fox (USA); Titular Members: P. Corradini (Italy), L. C. Cross (UK), N. A. Platé (USSR), W. Ring (FRG), G. J. Smets (Belgium), T. Tsuruta (Japan); Associate Members: N. M. Bikales (USA), A. D. Jenkins (UK), P. Sigwalt (France). nomenclature. When the first report was issued, the skeletal rules were adequate for most needs; indeed, most polymers could at that time be reasonably named on the basis of the substance used in producing the polymer. In the intervening years, however, the rapid growth of the polymer field has dictated a need for modification and expansion of the earlier rules. This report presents an updating of those rules. Necessarily, a great many changes in detail were required, since it is desirable that organic polymer nomenclature adhere as much as possible to the Definitive Rules for the Nomenclature of Organic Chemistry.,

These rules are designed to name, uniquely and 
unambiguously, the structures of regular single-strand organic polymers whose repeating structures can be written within the framework of ordinary chemical principles; stereochemistry is not considered in this report. As with organic nomenclature, this nomenclature describes chemical structures rather than substances. It is realized that polymeric substances ordinarily include many structures, and that a complete description of even a single polymer molecule would include an itemization of terminal groups, branching, random impurities, degree of steric regularity, chain imperfections, etc. Nevertheless, it is useful to think of a substance as being represented by a single structure that may itself be hypothetical. To the extent that the polymer structure can be portrayed as a chain of regularly repeating structural or constitutional repeating units (the terms are synonymous), the structure can be named by these rules; in addition, provision has been made for including end groups in the name.

In this report, the fundamental principles and the basic rules of the structure-based nomenclature are given first, accompanied by detailed extensions and applications. An Appendix is included containing a limiting list of acceptable source-based names, along with the corresponding structure-based names, of common polymers. The Commission sees no objection to the continued use of such source-based names where these names are clear and unambiguous, but prefers the use of the structurebased nomenclature detailed in these rules.

\section{FUNDAMENTAL PRINCIPLES}

This nomenclature system rests upon the selection of a preferred constitutional repeating unit $^{5}$ (abbreviation: $\mathrm{CRU})$ of which the polymer is a multiple; the name of the polymer is simply the name of this repeating unit prefixed by poly. The unit itself is named wherever possible according to the Definitive Rules for the Nomenclature of Organic Chemistry. ${ }^{3}$ For regular single-strand polymers, this unit usually is a bivalent group.

In using this nomenclature, the steps to be followed in sequence are (1) identify the CRU, (2) orient the CRU, and (3) name the CRU. Identification and orientation must always precede the selection of the name of the polymer.

\section{(1) Identification of the constitutional repeating unit}

There are many ways to write the CRU for most polymer structures. In simple cases, these units are readily identified

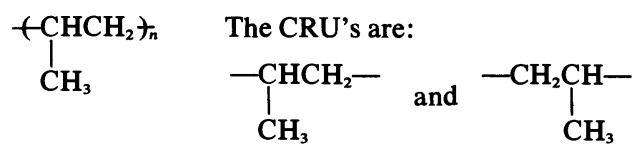

In more complex cases, it is often necessary to draw a large segment of the chain and from it choose all of the possible CRU's. For example, in the polymer
To allow construction of a unique name, a single CRU must be selected. The following rules have been designed to specify both seniority among subunits, i.e. the point at which to begin writing the CRU, and the direction along the chain in which to continue to the end of the CRU. The preferred constitutional repeating unit will be one beginning with the subunit of highest seniority (see Rule 2). From this subunit, one proceeds toward the subunit next in seniority. In the preceding example, the subunit of highest seniority is an oxygen atom and the subunit next in seniority is a substituted $-\mathrm{CH}_{2} \mathrm{CH}_{2}-$ unit. The parent $\mathrm{CRU}$ will therefore be either $-\mathrm{OCH}_{2} \mathrm{CH}_{2}-$ or $-\mathrm{CH}_{2} \mathrm{CH}_{2} \mathrm{O}$ Further choice in this case is based on the lowest locant for substitution, so that the CRU is

or<smiles>COCC(F)F</smiles><smiles>CCC(C)C(F)C(F)CCOC</smiles>

(2) Orientation of the constitutional repeating unit

The CRU is written to read from left to right. In the above example, the preferred CRU is therefore<smiles>CCC(F)OC</smiles>

\section{(3) Naming the constitutional repeating unit}

The name of the CRU is formed by citing, in order, the names of the largest subunits within the CRU (Rule 1.21). In the example, the oxygen atom is called oxy and the $-\mathrm{CH}_{2} \mathrm{CH}_{2}$ - (preferred to $-\mathrm{CH}_{2}-$ because it is larger and can be named as a unit) is called ethylene; the latter unit substituted with one fluorine atom is called 1fluoroethylene. The CRU in question is therefore named oxy(1-fluoroethylene), and the corresponding polymer is

$$
\underset{\text { I }}{\left.+\mathrm{OCH}_{2}\right)_{n}} \quad \text { Poly[oxy(1-fluoroethylene)] }
$$

The rules which follow are essentially directions for the selection of the CRU in a given polymer.

\section{RULE 1. THE CONSTITUTIONAL} REPEATING UNIT

Regular single-strand polymer chains can usually be represented as multiples of a bivalent repeating unit which can itself be named. The name of the polymer is poly(constitutional repeating unit). In those cases in which a choice is possible between a bivalent and a

the CRU's are
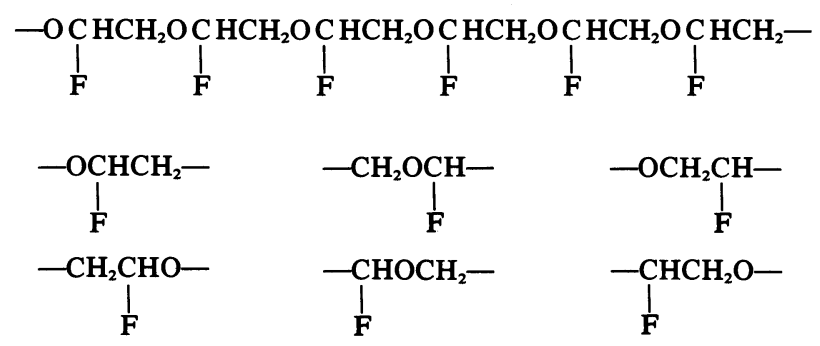
higher-valent CRU, the number of free valences $t$ is minimized only after all other orders of seniority have been observed. (See also Rule 2.12.)

but<smiles>C=CC=C1CNCC(=CC)C1</smiles>

is preferred to

is preferred to

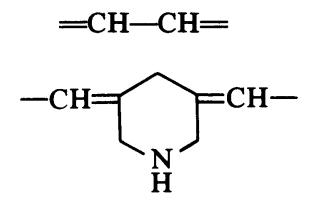

\subsection{The generic name}

Linear polymers of unspecified chain length will be named by prefixing poly to the name, placed in parentheses or brackets, of the structural repeating unit of the polymer, i.e. the smallest unit of which the polymer is a multiple. If the name of the repeating unit is "ABC", the corresponding polymer name is

$$
+\mathrm{ABC}_{\mathrm{n}} \quad \text { Poly(ABC) }
$$

Where it is desired to specify chain length, the appropriate Greek prefix (deca, docosa, etc.) may be used in place of poly. For a single-strand polymer, the CRU is named within the restriction of directional citation by the IUPAC organic nomenclature rules. ${ }^{3,4}$

\subsection{Simple constitutional repeating units}

1.21. The CRU may contain one or more subunits. Among the possible subunits or combinations of adjacent subunits, the largest possible group, based on main chain atoms and rings only, is to be named (see also Rule 2.11). When the largest group includes the entire CRU, its name, prefixed by poly is the name of the polymer.

$$
\begin{array}{cc}
\left(-\mathrm{CH}_{2}\right)_{n} & \text { Poly(methylene) } \\
\left(-\mathrm{OCH}_{2} \mathrm{CH}_{2}\right)_{n} & \text { Poly(oxyethylene) }
\end{array}
$$

The name of a CRU or any subunit has no relationship to the manner in which the unit was prepared; the name is simply that of the largest identifiable unit and any locants for unsaturation, substituents, etc. are dictated by the structure of the unit.

$$
\left.+\mathrm{CH}=\mathrm{CHCH}_{2} \mathrm{CH}_{2}\right)_{n}
$$

Poly(1-butenylene) (not poly(2-butenylene), which gives a higher locant to the double bond, nor poly(vinyleneethylene), which identifies less than the largest unit in the CRU)

1.22. Identification of the preferred CRU rests on (a) the kinds of atoms or rings in the main chain or (b) on the location of substituents when there is only one kind of main chain atom or ring. Orientation of the CRU in case (a) is determined by the rules of seniority given in Rule 2; in case (b), lowest locants (except when fixed numbering applies; see Rule 1.24) are given to substitutents in alphabetical order (Rule 2.42).

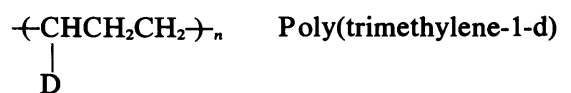

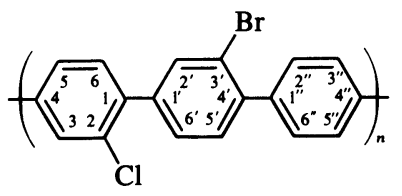

Poly(3'-bromo-2-chlorop-terphenyl-4,4"-ylene)

$\dagger$ In this document "free valence" means classical free valence.
After the CRU and its orientation, reading left to right, have been established, the CRU or its constituent subunits are named to include as many as possible, in order, of (a) the main chain atoms or rings and (b) the substituents within a single name (see also Rule 3.1).

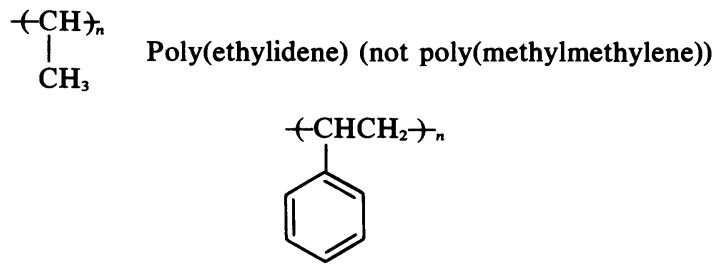

Poly(1-phenylethylene) (not poly(benzylidenemethylene) or poly(1-phenyldimethylene))<smiles>CCCC(C)=O</smiles>

Poly(1,2-dioxotetramethylene) (not poly(succinyl), since substituent positions 1,2 are preferred to 1,4 , and identification and orientation of the CRU precede formation of the name)<smiles>O=CCCC(=O)O</smiles>

Poly(oxysuccinyl) (not poly[oxy(1,4-dioxotetramethylene)], since succinyl is an approved name ${ }^{3}$ )

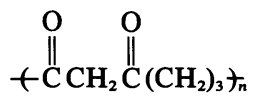

Poly(1,3-dioxohexamethylene) (not poly(malonyltrimethylene) because the six-carbon chain is the largest unit that can itself be named)

$$
+\mathrm{CH}=\mathrm{CH})_{n}
$$

Poly(vinylene) $\left(\right.$ not $\neq \mathrm{CH}-\mathrm{CH} \neq{ }_{n}$, poly(ethanediylidene)

1.23. If, after identification and orientation, the CRU is found to contain one or more acyclic bivalent groups having more than two hetero atoms in the main chain, these groups may often be advantageously named by replacement nomenclature. ${ }^{3}$ The main chain of the group is named and numbered as though the entire chain were an acyclic hydrocarbon and the hetero atoms are named by means of prefixes "aza", "oxa", etc. with locants to fix their positions.

$$
\stackrel{1}{\mathrm{O}}-\stackrel{2}{\mathrm{C}} \mathrm{H}_{2}-\stackrel{3}{\mathrm{C}} \mathrm{H}_{2}-\stackrel{4}{\mathrm{~N}} \mathrm{H}-\stackrel{5}{\mathrm{C}} \mathrm{H}_{2}-\stackrel{6}{\mathrm{~S}}-\stackrel{7}{\mathrm{C}} \mathrm{H}_{2}-\stackrel{8}{\mathrm{C}} \mathrm{H}_{2}-\stackrel{9}{\mathrm{~N}} \mathrm{H}-{ }_{n}
$$

Replacement name: Poly(1-oxa-6-thia-4,9-diazanonamethylene-1,3-cyclohexylene Systematic name: Poly(oxyethyleneiminomethylenethioethyleneimino - 1,3cyclohexylene) 
See Rules 2.14 and 2.32 for other examples of the use of replacement nomenclature.

1.24. Groups having fixed numbering retain that numbering in naming the CRU (see also Rules 2.22 and 2.41).

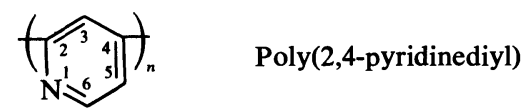

For most acyclic and monocarbocyclic groups, preference in lowest numbers is given to the carbon atoms having the free valences. In other families of compounds, notably the polycyclic hydrocarbons, bridged hydrocarbons, spiro hydrocarbons, and heterocyclic ring systems, numbering is fixed for the ring system. Free valences in groups are numbered as low as possible, consistent with the fixed numbering. Since direction through the bivalent group is a requisite parameter in naming polymers, the same fixed numbering is retained for either direction of progress through the group in generating the polymer name.

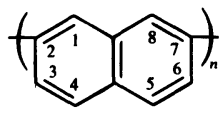

Poly(2,7-naphthylene) (not poly(7,2-naphthylene) or poly(3,6-naphthylene))<smiles>CC1C2CC3CC(C2)C1C3C</smiles>

Poly(tricyclo[2.2.1.0 $\left.0^{2.6}\right]$ hept-3,5-ylene)<smiles></smiles>

Poly(2H-furo[3,2-b]pyran-2,6-diyl)<smiles>CC1C2C3C4OC2(C4C)C13</smiles>

Poly(5-oxaspiro[3.5]non-2,7-ylene)

\section{RULE 2. CONSTITUTIONAL REPEATING UNITS HAVING TWO OR MORE SUBUNITS}

Many regular single-strand polymers can be represented as multiples of repeating units, such as $-\mathrm{ABC}$-, which consist of a series of smaller subunits, $-\mathrm{A}-,-\mathrm{B}-$, and -C-. The prototype name of the polymer is poly $(A B C)$, where $(\mathrm{ABC})$ stands for the names of $\mathrm{A}, \mathrm{B}$, and $\mathrm{C}$, taken in that order. This rule is concerned with the seniority of subunits in identifying the preferred CRU for a given polymer structure.

\subsection{Seniority of subunits and direction of citation}

2.11. Polymers having CRU's containing two or more subunits are named with the prefix poly followed in parentheses or brackets by the names of the largest possible subunits cited in order from left to right as they appear in the CRU. The CRU is written from left to right beginning with the subunit of highest seniority and proceeding in a direction defined by the shorter path to the subunit next in seniority.

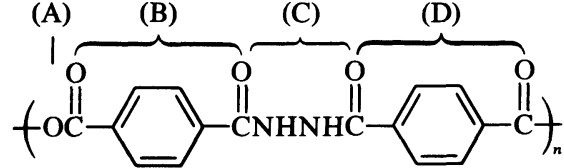

Poly(oxyterephthaloylhydrazoterephthaloyl) (not poly(oxycarbonyl-1,4-phenylenebicarbamoyl-1,4phenylenecarbonyl))

2.12. Usually the CRU in a regular single-strand polymer should be a bivalent group. The starting point for the unit is at the subunit of highest seniority, and citation will be in the direction of the shorter path toward that subunit or subunit combinations of highest seniority.

For citation of the first subunit, the order of seniority among the types of bivalent groups is (1) heterocyclic rings (see Rule 2.2), followed by (2) chains containing hetero atoms (see Rule 2.3), (3) carbocyclic rings (see Rule 2.4), and (4) chains containing only carbon, in that order. This order is unaffected by the presence of rings, atoms, or groups that are not part of the main chain, even though such substituents could be expressed as part of a trivial name for a bivalent group.<smiles>CC1=Cc2cc1nc(NC1CCC(C(C)c3ccccc3)CC1)n2</smiles>

Poly(4,2-pyridinediylimino-1,4-cyclohexylenebenzylidene)

2.13. Choice of direction along the main chain of the CRU is determined by the shorter path, counting ring and chain atoms individually, from the subunit of highest seniority to the subunit next in seniority.<smiles>Cc1ccnc(C(NC2CCCCC2)c2ccccc2)c1</smiles>

Poly(4,2-pyridinediylbenzylideneimino-1,4-cyclohexylene)

The possible paths between subunits of first and second seniority necessarily involve subunits of lesser seniority. Except in cases where two paths are of equal length (see Rule 2.14), the number rather than the nature of the atoms involved is the determining factor.

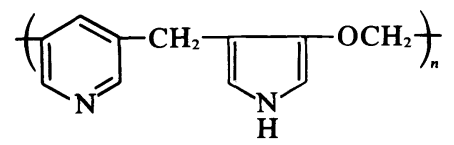

Poly(3,5-pyridinediylmethylenepyrrole-3,4-diyloxymethylene) (not poly(3,5-pyridinediylmethyleneoxypyrrole-3,4-diylmethylene), in which the longer $-\mathrm{CH}_{2} \mathrm{O}$ - path between rings is followed)

Where a ring constitutes all or part of a path, the shortest continuous chain of atoms in the ring is selected.

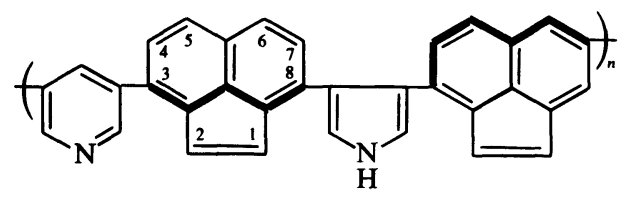

Poly(3,5-pyridinediyl-3,8-acenaphthylenylenepyrrole-3,4-diyl-3,7-acenaphthylenylene) (heavy line denotes path followed) 
2.14. When the choice of path determining direction of citation involves paths of equal length to subunits of equal seniority in the normal order of precedence, the choice of path depends upon the kind of subunits in the paths themselves. This condition applies to chains typified by the following generalized structures, where A, B, and C are subunits in that order of decreasing seniority, separated by paths of differing lengths $\mathrm{x}$ and $\mathrm{y}$ which contain units of lower seniority than $\mathrm{C}$ :

$$
\begin{gathered}
\text {-C-y-B-x-A-x-B-y-C- } \\
\text {-B-y-A-x-A-y-B- } \\
\text {-B-y-A-x-A-x-A-y-B- }
\end{gathered}
$$

The choice of direction is from a subunit $A$ to the nearest part of a path $\mathrm{x}$ having highest seniority, or, if two paths $\mathrm{x}$ are identical in every respect, to the nearest part of path $y$ having highest seniority, etc. until some point of difference is encountered. (See also Rules 2.24 and 2.32.)

Examples of direction of citation based on the constituent parts of paths of equal length:

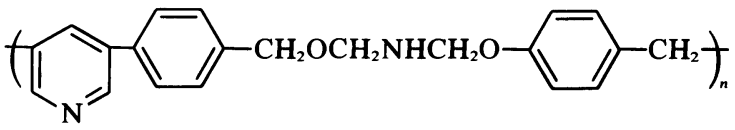

Poly(3,5-pyridinediyl-1,4-phenylenemethyleneoxymethyleneiminomethyleneoxy-1,4-phenylenemethylene) (choice of path from heterocyclic ring to $\mathrm{O}$ determined by position of phenylene)

\section{$\left.+\mathrm{OCH}_{2} \mathrm{OCH}_{2} \mathrm{NHCH}_{2} \mathrm{CH}_{2} \mathrm{SCH}_{2} \mathrm{NHCH}_{2} \mathrm{CH}_{2}\right)_{n}$}

Poly(oxymethyleneoxymethyleneiminoethylenethiomethyleneiminoethylene) or Poly(1,3-dioxa-8-thia-5, 10-diazadodecamethylene) (choice of path from $O$ to $S$ determined by position of $\mathrm{NH}$ )<smiles>CCOC1CCCC(c2cnccn2)C1</smiles>

Poly(3,5-pyridinediyl-1,3-cyclohexyleneoxytrimethylene) (a portion of a cyclic structure is senior to carbon chain of equal length)

Where substituents control the choice of CRU, the order of seniority is that given in Rule 2.42 .<smiles>CCCCCCCCCCCC(Cl)Cc1ccccc1</smiles>

Poly[thio(2-chlorotrimethylene)thiotrimethylene]<smiles>CC(CC(N)CCCc1ccccc1)C(=O)O</smiles>

Poly[thioethylenethio(2-amino-4-carboxypentamethylene)] (direction determined by alphabetical order)

$$
\left.+\mathrm{SCH}_{2} \mathrm{CH}_{2} \mathrm{SCHCH}_{2} \mathrm{CH}_{2} \mathrm{CHCH}_{2}\right)_{n}
$$

Poly[thioethylenethio(4-amino-1-carboxypentamethylene)] (direction determined by lowest locants takes precedence over alphabetical order)

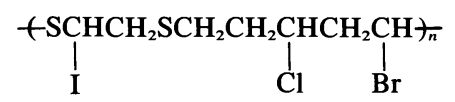

Poly[thio(1-iodoethylene)thio(5-bromo-3-chloropentamethylene)] (direction determined by the lower locant in the first cited subunit after beginning the CRU)

\subsection{Heterocyclic rings}

2.21. A CRU having two or more subunits that include a heterocyclic ring system in the main chain is named by citing first the heterocyclic ring group of highest seniority and proceeding by the shorter path in descending order of preference to (a) another of the same heterocyclic ring (see Rule 2.24)<smiles>CC1CC2COC(C1)C(Cc1cncc(Cc3cnccn3)c1)C2</smiles>

Poly[3,5-pyridinediylmethylene-3,5-pyridinediyl(tetrahydro-2H-pyran-3,5-diyl)]

(b) the heterocyclic ring next in seniority (see Rule 2.23)<smiles>CC1(C)C2CCC1C(c1cncc(-c3ccc4c(c3)Sc3ccccc3S4)c1)NC2</smiles>

Poly(2,6-morpholinediyl-3,5-pyridinediyl-2,8thianthrenediyl)

(c) the senior acyclic group containing a hetero atom in the main chain (see Rule 2.31)<smiles>c1ccc(OCc2cccnc2)cc1</smiles>

Poly(3,5-pyridinediylmethyleneoxy-1,4-phenylene)

(d) the senior carbocyclic ring system (see Rule 2.41)<smiles>c1cncc(-c2ccc(C3CCC4CC3C4)cc2)c1</smiles>

Poly(3,5-pyridinediyl-1,4-phenylene-1,2cyclopentylene)

and (e) the senior acyclic group containing only carbon in the main chain (see Rule 2.42)<smiles>CCOC(=O)c1cccnc1</smiles>

Poly(3,5-pyridinediylcarbonyloxymethylene)

2.22. Consistent with the fixed numbering of heterocyclic rings, the points of attachment to the main chain of the CRU should have the lowest permissible locants.

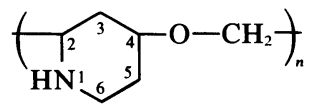

Poly(2,4-piperidinediyloxymethylene) 
<smiles>CCCOC1CC(C)CCN1</smiles>

Poly(4,2-piperidinediyloxymethylene)

Where there is a choice, the point of attachment at the left side of the ring should have the lowest permissible number.<smiles>CCCc1nnc(CC)[nH]1</smiles>

Poly(4H-1,2,4-triazole-3,5-diylmethylene)

2.23. Among heterocyclic ring systems, the descending order of seniority is (a) a ring system with nitrogen in the ring; (b) a ring system containing a hetero atom other than nitrogen as high as possible in the order given in Rule 2.31; (c) a ring system containing the greatest number of rings; (d) a ring system having the largest individual ring; (e) a ring system having the largest number of hetero atoms; (f) a ring system containing the greatest variety of hetero atoms; and $(\mathrm{g})$ the ring system having the greatest number of hetero atoms highest in the order given in Rule 2.31. This order is that followed in Rule B-2 of the IUPAC Rules. ${ }^{3}$<smiles></smiles>

Poly(4,2-pyridinediyl-4H-1,2,4-triazole-3,5diylmethylene)

Further examples of the application of seniority in heterocyclic ring systems are<smiles>c1ccc2c(c1)Nc1ccccc1O2</smiles>

Phenoxazine<smiles>c1ccc2nc3ccccc3nc2c1</smiles>

Phenazine<smiles>c1ccc2ncccc2c1</smiles>

Quinazoline<smiles>c1cncnc1</smiles>

Pyrimidine<smiles>c1ccc2c(c1)Oc1ccccc1S2</smiles>

Phenoxathiin
When two heterocyclic subunits differ only in degree of unsaturation, the senior subunit is that having the least hydrogenated ring system.<smiles>CC(C)(C)c1cncc(C2CC(C(C)(C)C)CCN2)c1</smiles>

Poly(3,5-pyridinediyl-2,4-piperidinediyl)

Among assemblies of identical heterocyclic rings, the ring of highest seniority is that having lowest numbers for the points of attachment between the rings within the assembly consistent with the fixed numbering of the parent ring.

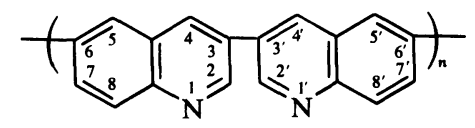

Poly[(3,3'-biquinoline)-6,6'-diyl $]$ (not poly[(6,6'biquinoline)-3,3'-diyl])<smiles>Cc1ccnc(-c2ccncn2)c1</smiles>

Poly[(2,3'-bipyridine)-4,5'-diyl](not poly[(2',3-bipyridine) $-4^{\prime}, 5$-diyl $]$ or poly $\left[\left(3^{\prime}, 4\right.\right.$-bipyridine $)-2,5^{\prime}$-diyl $\left.]\right)$.

Further choice is based on the number and kind of substituting groups (see Rule 2.42).<smiles>Cc1ccncc1-c1cncc(CC(C)(C)C)c1</smiles>

Poly[(4-chloro-3,3'-bipyridine-5,5'-diyl)methylene]

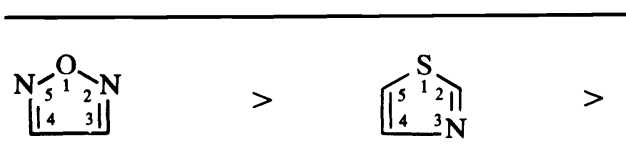

Furazan

Thiazole<smiles>c1cc2cc3c4ccccc4[nH]c3c3ccccc3c-2c1</smiles>

Carbazole<smiles></smiles>

Phthalazine<smiles>c1ccncc1</smiles>

Pyridine<smiles>c1ccoc1</smiles>

Furan<smiles>c1ccc2nnccc2c1</smiles>

Cinnoline<smiles>c1ncc2[nH]cnc2n1</smiles>

Purine<smiles>c1cc[nH]c1</smiles>

Pyrrole<smiles>c1ccsc1</smiles>

Thiophene 
2.24. When the CRU contains two identical rings of highest seniority or more than two such rings of highest seniority separated by identical paths, the direction of citation is determined by the shorter path to the subunit of second seniority. Further choice is based on the shorter path from that subunit to the subunit of third seniority, etc., as indicated in the order of seniority in Rule 2.21<smiles></smiles>

Poly(oxycarbonylnitrilo - 1,3 - propanediylidenenitrilocarbonyl)

Direction in a group such as azoxy $(-\stackrel{\mathrm{N}}{\uparrow}=\mathrm{N}-$ or $-\mathrm{N}=\mathrm{N}-)$ is

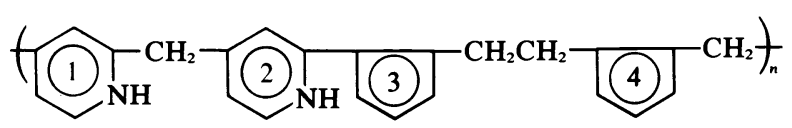

Poly(4,2-piperidinediylmethylene-4,2-piperidinediyl-1,2-cyclopentyleneethylene-1,2-cyclopentylenemethylene) (numbers in rings show order of preference in formation of name).

\subsection{Hetero atoms in chains}

2.31. Complex CRU's in which the senior subunit is a hetero atom or an acyclic chain with a hetero atom in the main chain are named by citing first the hetero atom of highest seniority and proceeding by the shorter path in descending order of seniority to (a) another hetero atom of the same kind; (b) the hetero atom next in seniority; (c) the senior carbocyclic ring system (see Rule 2.41); and (d) the senior acyclic group containing only carbon in the main chain (see Rule 2.42). For the most common hetero atoms the descending order of seniority is $\mathrm{O}, \mathrm{S}, \mathrm{Se}, \mathrm{Te}, \mathrm{N}, \mathrm{P}, \mathrm{As}$, $\mathrm{Sb}, \mathrm{Bi}, \mathrm{Si}, \mathrm{Ge}, \mathrm{Sn}, \mathrm{Pb}, \mathrm{B}$, and $\mathrm{Hg}$; other hetero atoms may be placed within this order as indicated by their positions in the periodic table.

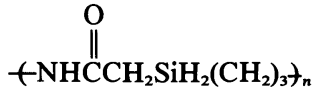

Poly[imino(1-oxoethylene)silylenetrimethylene]

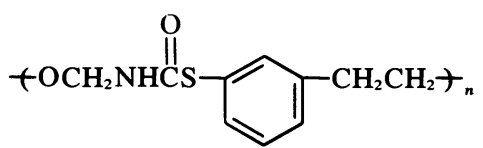

Poly(oxymethyleneiminocarbonylthio-1,3phenyleneethylene)

\section{$\left.+\mathrm{ONHCH}_{2} \mathrm{NHNHCH}_{2}\right)_{n}$}

Poly(oxyiminomethylenehydrazomethylene)

Parentheses must be used in some cases to prevent ambiguity.<smiles>O=C=CCS</smiles>

Poly[thio(carbonyl)] ("carbonyl" is enclosed in parentheses to differentiate the structure from $+\mathrm{C}_{f_{n}}$, poly(thiocarbonyl))

The direction of bonding in unsymmetrical single-atom radicals (e.g. $=\mathrm{N}-$ or $-\mathrm{N}=$ for nitrilo) is indicated by the endings of the names of the adjacent subunits in the CRU. indicated by the prefixes ONN or NNO, respectively, in that order of seniority.<smiles>[14CH3]OC[14N]N=[O+][O]</smiles>

Poly[oxymethylene-ONN-azoxy(chloromethylene)]

The unsymmetrical group $-\mathrm{N}=\mathrm{N}-\mathrm{NH}-$, designated "diazoamino" under the IUPAC Organic Rules, ${ }^{3}$ in the present directional nomenclature for polymers is called "azoimino".

Among hetero atoms of the same kind, the shortest path and direction between the hetero atoms is chosen first. For a choice between equal paths, the hetero atom of highest seniority is the one most highly substituted, with the order of substituent seniority being that given in Rule 2.42 .

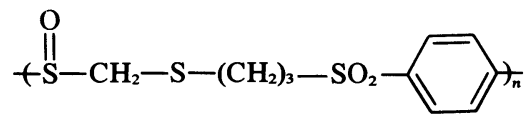

Poly(sulfinylmethylenethiotrimethylenesulfonyl-1,4phenylene)

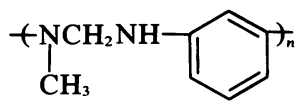

Poly[(methylimino)methyleneimino-1,3-phenylene $]$

2.32. If the CRU contains two or more hetero atoms of highest seniority or more than two such hetero atoms separated by identical paths, the direction of citation is determined by the shorter path to the subunit of second seniority. Further choice is based on the shorter path from that subunit to the subunit of third seniority, etc. as indicated in the order of seniority in Rule 2.31.

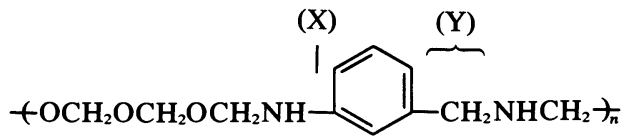

Poly(oxymethyleneoxymethyleneoxymethyleneimino1,3-phenylenemethyleneiminomethylene) or poly(1,3,5trioxa-7-azaheptamethylene-1,3-phenylene-2-

azatrimethylene) (the shorter path $\mathrm{x}$ between the $\mathrm{NH}$ group and the ring has been taken)

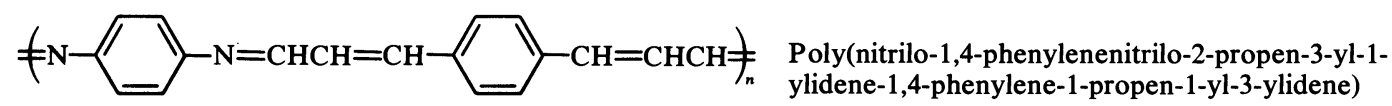




\subsection{Carbocyclic rings and carbon chains}

2.41. Constitutional repeating units in which the senior subunit is a carbocyclic ring system are named by citing first the carbocyclic ring of highest seniority and proceeding by the shorter path, in descending order of seniority, to (a) another of the same carbocycle; (b) the carbocyclic system next in seniority; and (c) the acyclic group appearing earliest in the alphabet. Carbocyclic ring system seniority is based on complexity, with the ring system of highest seniority being that containing the largest number of rings. Further order of seniority is based on (a) the largest individual ring at the first point of difference; (b) the largest number of atoms common to the rings; (c) the lowest locant numbers at the first point of difference for ring junctions, and (d) the least hydrogenated ring. The basis for further choice is found in Rule C-14.1 of the IUPAC Rules. ${ }^{3}$ The direction of citation in CRU's having two or more carbocycles of highest seniority is determined in a manner analogous to that of Rule 2.32 .<smiles>CC1CCC(c2ccc(-c3ccc4ccccc4c3)cc2)CC1</smiles>

poly(2,7-naphthylene-1,4-phenylene-1,3cyclohexylene)

Examples of the application of seniority rules in carbocyclic ring systems:

(a) Largest number of rings:<smiles>c1ccc2c(c1)Cc1ccccc1-2</smiles>

Fluorene is senior to

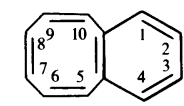

Benzocyclooctene (b) Largest individual ring at the first point of difference<smiles>c1ccc2ccccc2c1</smiles>

Naphthalene is senior to

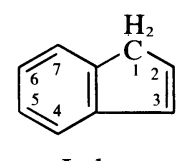

Indene (c) Largest number of atoms common to the rings:

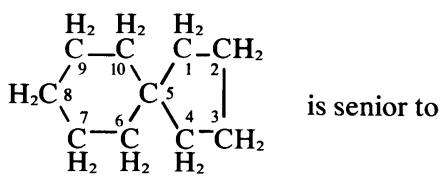

Spiro[4.5]decane

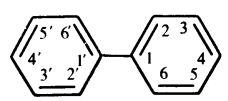

Biphenyl (d) Lowest locant numbers at the first point of difference for ring junctions:

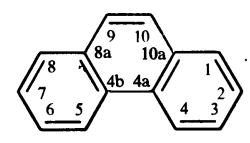

Phenanthrene

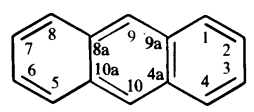

Anthracene is senior to

(e) Lowest state of hydrogenation.<smiles>c1ccccc1</smiles>
is senior to<smiles>C1=CCCCC1</smiles>
is senior to<smiles>C1CCCCC1</smiles>

Benzene
Cyclohexane
More than one numbering method may be in use in certain ring systems, such as the spiro hydrocarbons. Generally, in a specific ring system, a ring with unprimed locants is senior to one with primed locants. Points of attachment to the main chain of the CRU receive lowest permissible numbers.<smiles>CCCC1C2CCC3(C4CCCC4)CC2CC13</smiles>

Poly(spiro[4.5]dec-2,8-yleneethylene) (repeating unit named by IUPAC Rule A-41)<smiles>COC1C=CC2C(C3CCCC3)C=CC12</smiles>

Poly(oxyspiro[3.5]nona-2,5-dien-7,1-ylene-4cyclohexen-1,3-ylene)<smiles>CCCc1ccccc1-c1ccccc1</smiles>

Poly(2,6-biphenylyleneethylene)<smiles></smiles>

Poly[(5'-chloro-1,2'-binaphthyl-4,7'ylene)methylene]<smiles>Cc1ccc(-c2ccc(Cc3ccc(CC(C)(C)C)cc3)cc2)cc1Cl</smiles>

Poly[(3-chloro-4,4'-biphenylylene)methylene(3chloro-1,4-phenylene)methylene] (not poly [(3'-chloro4,4'-biphenylylene)methylene(2-chloro-1,4phenylene)methylene]; the substituent in the preferred ring determines the direction)

2.42. When equal paths lead through two of the same acyclic subunits, choice of direction is determined, in descending order, by (a) the acyclic chain with the largest number of substituents<smiles>COC(Cl)(Cl)CNC(C)=O</smiles>

Poly[oxy(1,1-dichloroethylene)imino(1-oxoethylene)]

(b) the chain having substituents with lowest locants<smiles>CC(Cl)c1cccc(C(Cl)Cl)c1</smiles>

Poly[thio(1-chloroethylene)-1,3-phenylene(1chloroethylene)] 
and (c) the alphabetical order of substituents<smiles>CCCCCCCCC(Br)c1ccccc1</smiles>

Poly[1,3 - phenylene(1 - bromoethylene) - 1,3 cyclohexylene( 2 - butylethylene)]

\section{RULE 3. SUBSTITUENTS}

3.1. Substituents to acyclic or cyclic subunits in the main chain of the CRU are included within the trivial name of the subunit whereever such name is approved by the IUPAC Organic Rules ${ }^{3}$ (see also Rule 1.22).

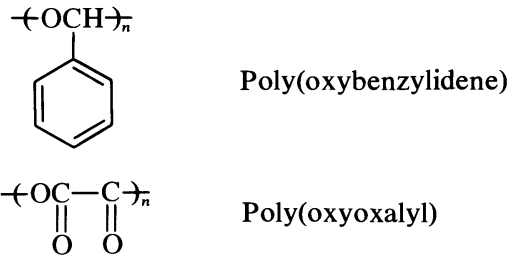

3.2. Substituents along the main chain other than those included in the name of a subunit are denoted by means of prefixes appended to the name of the subunit to which they are bound. In groups not having numbering fixed by other criteria, lowest locants appear at the left side of the group as written in the CRU (See also Rule 2.14).<smiles>CCC(Br)c1ccc(Cl)cc1</smiles>

Poly[(6 - chloro - 1 - cyclohexen - 1,3 - ylene) (1 bromoethylene)] (not Poly[(6 - chloro - 1 - cyclohexen $3,1$ - ylene) ( 2 - bromoethylene $)]$ )

Functional derivatives that are clearly a part of the CRU are named as substituents to the appropriate subunit by the use of prefixes.

$\begin{array}{ll}+\mathrm{OCH})_{n} & \text { Poly[oxy[2-(methoxycarbonyl)- } \\ \mathrm{CH}_{2} \mathrm{COOCH}_{3} & \text { ethylidene]] }\end{array}$

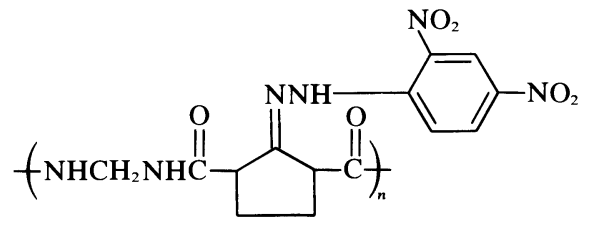

Poly[iminomethyleneiminocarbonyl[2 - [(2,4 - dinitrophenyl)hydrazono] - 1,3 - cyclopentylene]carbonyl]

3.3. Salts and onium compounds of polymers are named by placing the appropriate prefix or suffix together with the name of the CRU in the enclosed part of the polymer name.

$\begin{array}{ll}\left.\right|_{\mathrm{COO}^{-} \mathrm{Na}^{+}} ^{\left(\mathrm{CHCH}_{2}\right)_{n}} & \text { Poly(sodium 1-carboxylatoethylene) } \\ \left.\right|_{\mathrm{CH}_{3}} ^{\mathrm{CH}_{3}} \mathrm{Br}^{-} & \begin{array}{l}\text { Poly[(dimethyliminio)ethylene } \\ \text { bromide] }\end{array}\end{array}$

Certain substituents are frequently expressed as part of a trivial name. The subunit thus named can itself be further substituted without altering the original trivial name.

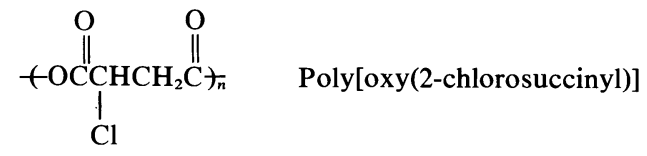

The same (in this case, doubly-bonded oxygen) substituents not expressed in a trivial name have no special seniority.<smiles>[NH2+]=NC(=O)c1ccccc1</smiles><smiles>CNC(Cl)C(=O)c1ccc([N+](=O)[O-])c(CCC(C)Br)c1</smiles>

Poly[imino(1 - chloro - 2 - oxoethylene) (4 - nitro - 1,3 phenylene) (3 - bromotrimethylene)]

Substituents in unknown positions in specific subunits are named in the usual way but either without locants or with an $x$ locant.<smiles>Cc1ccc(NC(=O)CCC(C)(C)C)cc1NC(C)(C)C</smiles>

Poly[imino(methyl(or $x$ - methyl) - 1,3 - phenylene)iminomalonyl]<smiles>C1CCCCC1</smiles>

Poly $(x$ - imino - 1,2 - cyclopentylene) (the $x$ is required to differentiate this structure from $+\mathrm{NH} \longrightarrow]^{)_{n}}$ poly(imino-1,2-cyclopentylene))

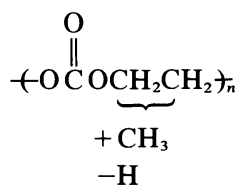

Poly[oxycarbonyloxy(methylethylene)] (position of the methyl not stated)

3.4. End groups may be specified by prefixes placed ahead of the name of the polymer. The end group designated by $\alpha$ is that attached to the left side of the CRU written as described in the preceding rules; the other end group is designated by $\omega$.

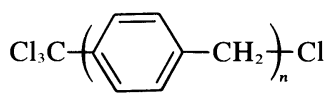

$\alpha$ - (Trichloromethyl) - $\omega$ - $\operatorname{chloropoly(1,4}$ phenylenemethylene) 
Acknowledgement-The Commission acknowledges its debt to the Committee on Nomenclature of the Division of Polymer Chemistry of the American Chemical Society, whose efforts resulted in a general updating and extension of the 1952 IUPAC Polymer Rules. ${ }^{1}$ The updated rules appeared in Macromolecules 1, 193-8 (1968).

\section{REFERENCES}

${ }^{1}$ International Union of Pure and Applied Chemistry, Physical Chemistry Division, Commission on Macromolecules, Subcommission on Nomenclature. Report on nomenclature in the field of macromolecules, J. Polymer Sci. 8(3), 257-77 (1952).

${ }^{2}$ International Union of Pure and Applied Chemistry, Physical Chemistry Division, Commission on Macromolecules, Subcommission on Nomenclature. Report on nomenclature dealing with steric regularity in high polymers, Pure Appl. Chem. 12, 645-56 (1966); Bull. Soc. Chim. Fr. 7, 2127-32 (1965).

${ }^{3}$ International Union of Pure and Applied Chemistry, Nomencla ture of Organic Chemistry. Sections A, B and C, third edition. Butterworths, London (1971).

${ }^{4}$ International Union of Pure and Applied Chemistry, Rules for the nomenclature of organic chemistry. Section E. Stereochemistry (1974 Recommendations). Pure Appl. Chem. 45, 11-30 (1976). SInternational Union of Pure and Applied Chemistry, Macromolecular Division, Nomenclature Commission. Basic definitions of terms relating to polymers, Pure Appl. Chem. 40(3), 477-91 (1974).

\section{APPENDIX A}

\section{SYSTEMATIC AND SOURCE NAMES FOR COMMON POLYMERS}

The Commission recognized that a number of common polymers have semisystematic or trivial names that are well established by usage; it is not intended that they be immediately supplanted by the structure-based names. Nevertheless, it is hoped that for scientific communication the use of semisystematic or trivial names for polymers will be kept to a minimum.

For the following idealized structural representations, the semisystematic or trivial names given are approved for use in scientific work; the corresponding structure-based names are given as alternative names. Equivalent names for close analogs of these polymers (e.g. other alkyl ester analogs of poly(methyl acrylate)) are also acceptable. Where the semisystematic name is an obvious source-based name, the polymer referred to is that derived from the indicated source.

$$
\begin{gathered}
\left(\mathrm{CH}_{2} \mathrm{CH}_{2}\right)_{n} \\
\text { polyethylene } \\
\text { poly(methylene) } \\
\left.+\mathrm{CHCH}_{2}\right)_{n} \\
\mathrm{CH}_{3}
\end{gathered}
$$

polypropylene poly(propylene)<smiles>CCC(C)(C)C</smiles>

polyisobutylene poly(1,1-dimethylethylene)

$$
\begin{gathered}
\left(\mathrm{CH}=\mathrm{CHCH}_{2} \mathrm{CH}_{2}\right)_{n} \\
\text { polybutadiene } \\
\text { poly(1-butenylene) }
\end{gathered}
$$<smiles>CC=CCC</smiles>

polyisoprene

poly(1-methyl-1-butenylene)<smiles>CCc1ccccc1</smiles>

polystyrene

poly(1-phenylethylene)<smiles>CCCCCCCCC#N</smiles>

polyacrylonitrile poly(1-cyanoethylene)

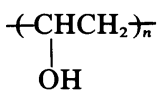

poly(vinyl alcohol) poly(1-hydroxyethylene)<smiles></smiles>
poly(vinyl acetate) poly(1-acetoxyethylene)<smiles>CCC(Cl)Cl</smiles>

poly(vinyl chloride) poly(1-chloroethylene)<smiles>CCC(F)(F)F</smiles>

poly(vinylidene fluoride) poly(1,1-difluoroethylene)

$$
\left.+\mathrm{CF}_{2} \mathrm{CF}_{2}\right)_{n}
$$

poly(tetrafluoroethylene) poly(difluoromethylene)

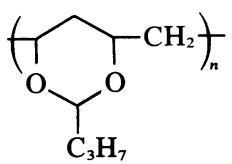

poly(vinyl butyral)

poly[(2-propyl-1,3-dioxane-4,6-diyl)methylene]

$$
\begin{gathered}
\left(\mathrm{CHCH}_{2}\right)_{n} \\
\text { poly(methyl acrylate) } \\
\text { poly[1-(methoxycarbonyl)ethylene] } \\
\text { poly[1-(methoxycarbonyl)-1-methylethylene] } \\
\text { poly(methyl methacrylate) }
\end{gathered}
$$


$\left.+\mathrm{OCH}_{2}\right)_{n}$

polyformaldehyde

poly(oxymethylene)

$\left.+\mathrm{OCH}_{2} \mathrm{CH}_{2}\right)_{n}$

poly(ethylene oxide)

poly(oxyethylene)

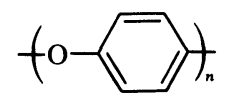

poly(phenylene oxide) poly(oxy-1,4-phenylene)

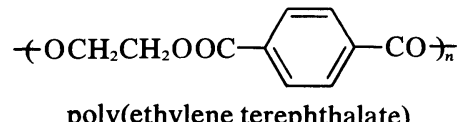

poly(ethylene terephthalate) poly(oxyethyleneoxyterephthaloyl)

\section{$\left.+\mathrm{NHCO}\left(\mathrm{CH}_{2}\right)_{4} \mathrm{CONH}\left(\mathrm{CH}_{2}\right)_{6}\right)_{n}$}

poly(hexamethylene adipamide)

poly[imino(1,6 - dioxohexamethylene)imnohexamethylene]

or

poly(iminoadipoyliminohexamethylene)

$\left.+\mathrm{NHCO}\left(\mathrm{CH}_{2}\right)_{5}\right)_{n}$

$\operatorname{poly}(\epsilon$-caprolactam)

poly[imino(1-oxohexamethylene)] 